ppi $201502 Z U 4645$

Esta publicación científica en formato digital es continuidad de la revista impresa ISSN-Versión Impresa 0798-1406 / ISSN-Versión on line 2542-3185Depósito legal pp $197402 Z$ U34
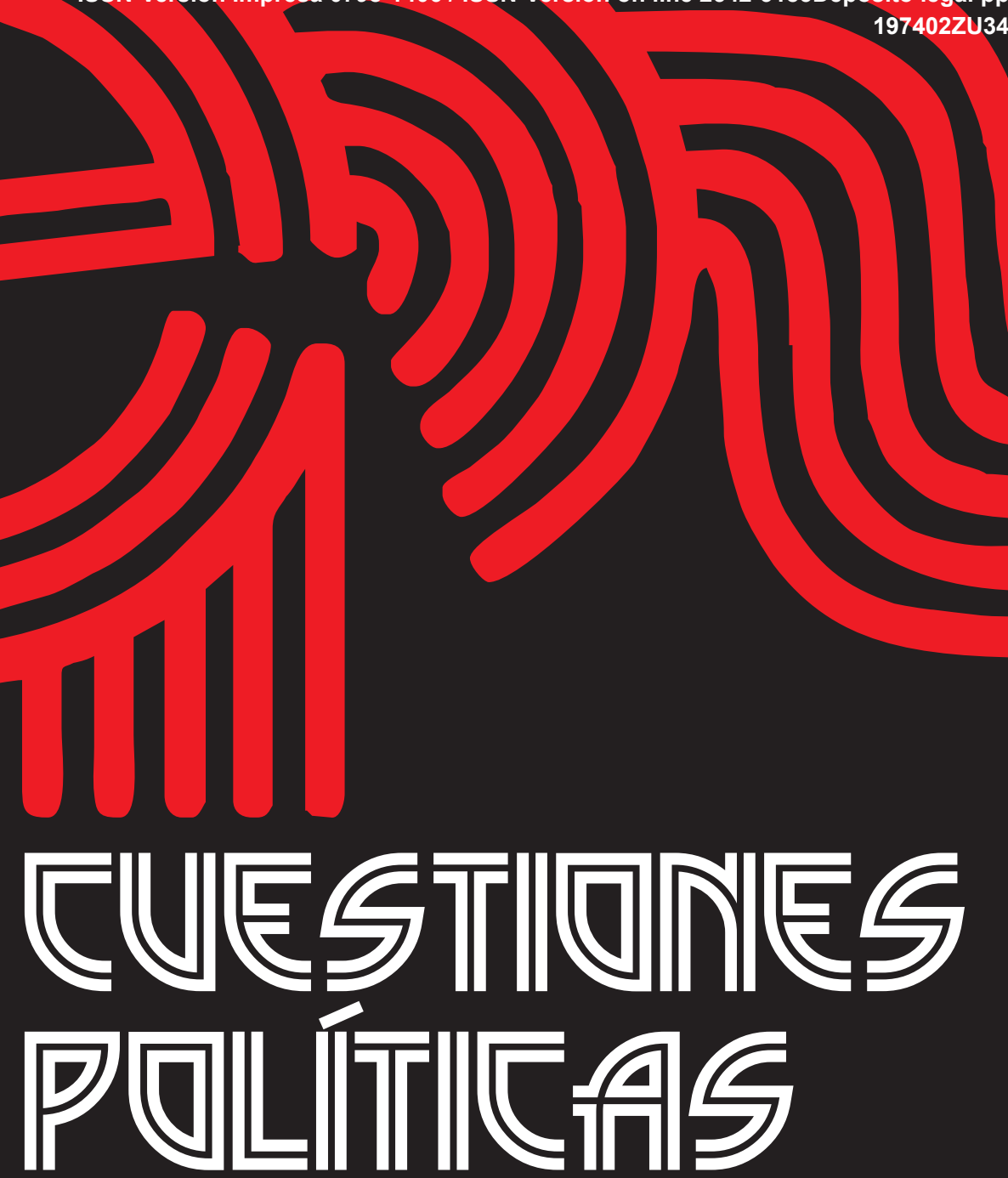

Instituto de Estudios Políticos y Derecho Público "Dr. Humberto J. La Roche" de la Facultad de Ciencias Jurídicas y Políticas de la Universidad del Zulia Maracaibo, Venezuela
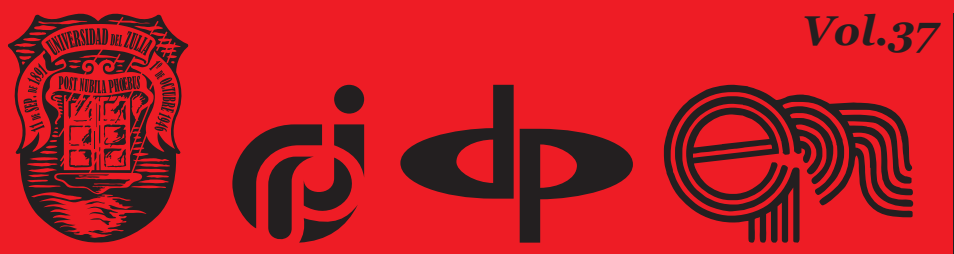

\title{
No 65
}

Julio

Diciembre 


\title{
Iglesia católica y política en América Latina: la teología de la liberación *
}

\author{
https://doi.org/10.46398/cuestpol.3865.03
}

Sofia, Pasquale **

\section{Resumen}

El trabajo analiza la posición de la Iglesia católica como actor político en América Latina luego de la Segunda guerra mundial hasta la década de los ochenta, con un enfoque específico sobre la Teología de la Liberación. Es una investigación analítico crítica con base documental, donde se consideran los elementos teológicos y filosóficos que han engendrado esta teología política. En ella, se produce una narrativa de los textos sagrados cristianos a partir del hombre concreto en situación de pobreza en esta región, con un enfoque denominado "recentramiento antropológico". Su carácter político en general, se expresa en la "opción preferencial por los pobres" enmarcada en el Concilio Vaticano II y en la Populorum Progressio de Pablo VI. Hay ramas moderadas como la Teología del Pueblo y otras más radicales que se fundamentan en el método marxista de la "lucha de clases" y de la "vía violenta", como medios para solucionar la causa social. El resultado es un enfrentamiento entre el método marxista y el método de la Doctrina social de la Iglesia para la solución de los problemas de la pobreza e indirectamente de la dependencia, donde se evidencia la "inconciliabilidad epistemológica" entre la doctrina marxista y la doctrina cristiana.

Palabras claves: Iglesia católica; teología de la Liberación; América Latina; marxismo; política.

* El presente artículo forma parte del proyecto de investigación intitulado: Iglesia Católica y Política en América Latina. La Teología de La Liberación, adscrito al Instituto de Estudios Políticos y Derecho Público, Facultad de Ciencias Jurídicas y Políticas; registrado en VAC-CONDES-CH-0146-17, Universidad del Zulia, Maracaibo -Venezuela.

** Doctor en Filosofía de la Pontificia Universidad Gregoriana de Roma-Italia. Docente Investigador de la Universidad del Zulia, Facultad de Ciencias Jurídicas y Políticas, Escuela de Ciencia Política. ORCID ID: https://orcid.org/oooo-003-0345-908X. Email: pakisofia@gmail.com 
Pasquale Sofia
48 Iglesia católica y política en América Latina: la teología de la liberación

\title{
Catholic Church and Politics in Latin America: Liberation Theology
}

\begin{abstract}
The work analysis the position of the Catholic Church as a political actor in Latin America after the Second World War until the eighties, with a specific focus on Liberation Theology. It is a documentary-based critical analytical investigation, where the theological and philosophical elements that have engendered this political theology are considered. In it, a narrative of the Christian sacred texts is produced from the concrete man in a situation of poverty in this region, with an approach called "anthropological re-centering". Its political character in general is expressed in the "preferential option for the poor" framed in the Second Vatican Council and in the Populorum Progressio of Paul VI. There are moderate branches such as People's Theology and other more radical ones that are based on the Marxist method of the "class struggle" and the "violent way", as means to solve the social cause. The result is a confrontation between the Marxist method and the method of the Social Doctrine of the Church for the solution of the problems of poverty and indirectly of dependency, where the "epistemological irreconcilability" between Marxist doctrine and Christian doctrine is evidenced.
\end{abstract}

Keywords: Catholic Church; Liberation theology; Latin America; Marxism; politics.

\section{Introducción al contexto histórico latinoamericano post Segunda guerra mundial. Entre Desarrollismo y Modernización}

Al finalizar la Segunda guerra mundial, América Latina lidiaba entre la modernidad versus la ruralidad, la modernización versus el subdesarrollo. Todo ello en medio del juego político y geopolítico de las dos superpotencias antagónicas del planeta, Estados Unidos de América y la U.R.S.S., quienes habían generado la nombrada Guerra Fría. En ese contexto, la Iglesia católica latinoamericana debía confrontar situaciones políticas diversas de país a país en el continente, que se desplazaban entre momentos de autoritarismo, momentos de dictadura, frágiles democracias (décadas del 50 al 80) hasta los "gloriosos 90", periodo de importantes reformas políticas y de recuperación de la democracia. Todas estas situaciones de enfrentamiento político y ambientes muy radicalizados ideológicamente al interior de los países de América Latina, se reflejaban en divisionismo en la Iglesia y en su papel evangelizador. 
Los índices elevados de pobreza y miseria al sur del Rio Grande, priorizaban explicaciones e intervenciones públicas desde teorías económicas con impacto social favorable. Desarrollismo y modernización fueron las teorías dominantes. Entre Marx y Keynes se debatían las tesis del desarrollismo económico en América Latina, apareciendo con vigor al inicio de la década de los Cincuenta el Manifiesto de la Habana de Prebisch y Singer (1950).

El documento, presentado por Raúl Prebisch, primer Secretario Ejecutivo de la Comisión Económica para América Latina y el Caribe (CEPAL), organismo regional de la ONU, se apoyaba en las tesis del economista Hans Singer quien describió, con método estadístico, el inicuo intercambio de los países exportadores de materia prima y los países manufactureros del primer mundo. Este tipo de intercambio expresaba la dependencia y el retardo que la región tenía respecto a sus partners norteamericanos y europeos, a los cuales estaban destinadas las materias primas producidas, lo cual generaba una comercialización desigual. El Manifiesto de la Habana asumió así no solamente una valencia científica económica y social relevante, sino también ética, entre un centro industrializado y una periferia proveedora de materia prima. El ideario generado por el documento constituyó la punta de lanza para los movimientos políticos de izquierda de Latinoamérica. La tesis Prebisch-Singer fue apoyada en toda América Latina por economistas anticapitalista como: Cardoso, Dos Santos, Faletto, Pinto Santa Cruz, Frank, Urquidi, Ferrer, entre otros; algunos de los mencionados, en los años Noventa, revisaron sus posturas radicales hacia visiones más progresistas.

Así que, en línea con el relativo éxito ya experimentado por la teoría de Keynes, al final de los años 60 se insistía en la intervención del Estado y en su control y regulación sobre las políticas fiscales y la dirección de la economía, institucionalizando el capitalismo de Estado; esto conllevaría la creación de empresas estratégicas y nacionalización de las que eventualmente ya existían, además de la regulación bancaria. En el tiempo este modelo económico se asociaría a hiperinflación y consiguientes crisis económicas e inestabilidad política en América Latina.

Como un desafío a la teoría de la Dependencia se desarrollaría la teoría liberal de la Modernización (años 50 y 60), que se concretaría en el famoso plan de financiamiento a las economías de América Latina, denominado Alianza para el Progreso (1961-1970), del presidente Kennedy. Tal teoría se anclaba en las cinco tesis de Walter W. Rostow descritas en su texto Las etapas del crecimiento económico (1960), para el crecimiento económico basado en capitalismo y empresa. Si bien el proyecto Alianza para el Progreso promovía la evolución económica y el desarrollo de la democracia en el continente latino, al igual que la propuesta dependentista, no produjo los resultados esperados. 


\section{Pasquale Sofia \\ 50 Iglesia católica y política en América Latina: la teología de la liberación}

En esta dialéctica de desarrollo y subdesarrollo un hecho político importante lo constituyó la alineación de la revolución cubana con el marxismo leninismo. Por primera vez el continente sería el epicentro de la amenaza de un conflicto nuclear entre EUA y URSS (Crisis de los misiles, 1962). Con este evento la política reconquistaría frente a la economía, su centralidad en América Latina y en el mundo, así como la misma América Latina entra en la estrategia global de las potencias.

\section{El Catolicismo Social y la Teología de la Liberación}

Los filósofos franceses Jacques Maritain y Manuel Mounier, de forma diferente, han tenido gran influencia en los movimientos católicos latinoamericanos del siglo pasado. Ambos pensadores proponen un cambio de perspectiva a partir del ser humano y de la misma Iglesia, como exigencia existencial e interpretativa frente a los "signos de los tiempos".

Los partidos democratacristianos hacen de los textos de filosofía política de Maritain su Biblia, planteando reconstruir las sociedades a través de un renovado humanismo integral anclado en los valores cristianos originarios y adaptados a las necesidades del hombre contemporáneo. Mounier, por su lado, era partidario de un cambio radical en la filosofía del Estado y del papel teleológico-pastoral de la Iglesia, que desembocarían en una alianza entre fe y acción. El modelo de la nueva cristiandad, el nuevo lazo entre fe y razón-acción, debía realizarse, para él, en unión del ideal cristiano con el ideal socialista, directo heredero terrenal del empeño y anhelo cristiano. Para Mounier, la fe se transforma además en instrumento de acción humana, de liberación de la "servidumbre egipcia" del pueblo de Dios, como lo expresara San Lucas. El evangelista refiere que Jesús, leyendo del libro del profeta Isaías, dice que ha venido "para llevar la buena noticia a los pobres; a anunciar libertad a los presos y a dar vista a los ciegos; a dar libertad a los oprimidos" (Lc. 4, 18). Mounier historiza las palabras de Jesús en el siglo XX y lo dirige hacia el rescate de los proletarios y de los pobres, como lo anuncia en su propuesta para la constitución de un socialismo personalista.

Los dos pensadores coinciden en exigir un verdadero cambio estructural en el pensar y actuar de los católicos, dando inicio al surgimiento de una "teología de la acción", que propiamente en América Latina encontrará terreno fértil en buena parte de las comunidades eclesiales, hasta ser reelaborada en clave crítica autóctona, en función de las realidades peculiares de la sociedad latinoamericana. Iniciada antes del Concilio Vaticano II, la reflexión eclesiológica sobre la función de la teología da inicio a movimientos internos a la Iglesia católica que hasta el presente inspiran el quehacer a los católicos, frente a los acontecimientos históricos en esta parte del mundo. 
Desde estos debates sobre la interpretación de la relación Dios/hombre, y entre Iglesia/política/sociedad, varios fueron los teólogos del pre y post Concilio que comienzan la arquitectónica conceptual de movimientos latinoamericanos de renovación eclesial y político. De estos fermentos surgirían, por un lado, partidos políticos y, por el otro, el movimiento teológico de renovación denominado Teología de la Liberación. Al respecto señala el jesuita Martin Maier, "Hablar de la teología en América Latina después del Concilio Vaticano II es hablar de la teología de la liberación" (Maier, 1999: 146). Movimiento vasto y no uniforme, que hace referencia con su nombre a la liberación integral del hombre de sus condiciones de pobreza y miseria, de exclusión, de abandono y sumisión, y que promueve un rol más activo de la Iglesia en la sociedad de América Latina y del mundo.

Se trata no sólo de la liberación del pecado -misión primaria de la evangelización-, sino también "liberación" de las estructuras políticas y sociales injustas, generadas por el mismo pecado del hombre. De esa manera, y continuando la línea ya adelantada por los primeros frailes desembarcados en el continente, se aspiraba a una nueva Iglesia que, con sus fieles, luchase por la trasformación de la realidad que oprime, tiraniza y humilla al ser humano. Dividida entre una matriz católica y protestante, esta teología no ha tenido una línea única ni ha expresado siempre coherencia, siendo el resultado de una multiplicidad de situaciones nacionales de América Latina y de influencias europeas a veces en contraste entre ellas. Saranyana a tal propósito nota:

La TL (Teología de la Liberación) ha tenido diversas etapas, como todos reconocen; ha habido TL católica y TL protestante; y, además, los cultores de la TL han expresado tesis teológicas diversas y, sobre todo, han tenido intereses teológicos dispares e incluso contradictorios. Todo ello complica un tanto la especificación de este marco teológico. Por ello, quizá sea exacto hablar de un conjunto de teologías latinoamericanistas - unas más próximas a la TL que otras, aunque todas con una fuerte carga soteriológica y reivindicativa- (...) (Saranyana, 2002: 256).

Surge así una distinta interpretación de la función de la fe en la historia, que en varias ocasiones y países de Latinoamérica asumiría formas extremas y radicales, según la más o menos estricta alianza con el ideal y método marxista de la revolución o por la oposición a regímenes militares despóticos, que conllevaría a varios sacerdotes a involucrarse en la lucha armada para generar los cambios dentro de las sociedades del continente. Este nuevo fermento dentro del catolicismo latinoamericano tiene la intención de llevar la teología a la praxis histórica, creando una teología de la praxis.

Si bien esta teología aparece formalmente luego de la Segunda reunión del CELAM en Medellín (1968), donde se trató más específicamente de la reconversión de la teología, su gestación ha sido anterior; derivaba como se 


\section{Pasquale Sofia \\ 52 \\ Iglesia católica y política en América Latina: la teología de la liberación}

ha visto, de las inquietudes del existencialismo cristiano, del neotomismo, de la Doctrina Social, de los varios Concilios provinciales y diocesanos, cuyas raíces hermenéuticas se hallan en el Éxodo y en las palabras de Jesús.

\section{Entre fe y razón, teoría y praxis}

Centrados en las palabras de Jesús, el vino "a poner en libertad a los oprimidos" (Lc. 4:18) se inicia la nueva reflexión y problematización de la dialéctica fe-realidad. Es éste el punto de partida de la Teología de la Liberación. Jesús no sólo libera al hombre del pecado, no sólo salva su alma, Él salva al hombre integral, formado de espíritu y cuerpo, por ende, lo libera de la esclavitud y del dominio de un hombre sobre otro. La misión del sacerdote y de la Iglesia no es exclusivamente soteriológica respecto al alma, sería también la de salvar al hombre de todos aquellos vínculos -opresión, pobreza, exclusión- que impiden su desarrollo espiritual y material, para conducirlo hacia la tierra prometida de la liberación, como hizo Moisés con el pueblo hebreo en el (Éxodo).

Esta teología tiene una larga retrospectiva histórica. Desde Erasmo de Rotterdam, pasando por el sermón de Montesinos, por las Leyes de Burgos, por las doctrinas de la Escuela de Salamanca, hasta Juan Germán Roscio. Erasmo situó una base importante: educaba a príncipes y pueblo, para crear mentes analíticas y críticas frente a instituciones y doctrinas. El sermón del padre Montesinos ha sido considerado el primer grito de rebeldía contra una situación de degradación moral de los colonos españoles en América. Las Leyes de Burgos, productos de la acción del mismo fraile dominico, garantizaban los derechos naturales básicos de los indios, en tanto, la Escuela de Salamanca con sus doctrinas, apoyaría la causa indígena. Todo lo cual fortalecería las teorías de Suárez y Mariana en torno al derecho a la resistencia contra la opresión, y al tiranicidio como eventual respuesta frente al despotismo. Igualmente cuestionarían el origen divino del monarca, su soberanía y su derecho a gobernar contra la voluntad del pueblo. J. G. Roscio (1763-1821), a partir de la revisión de las Escrituras “con miras puramente políticas", demostraría en su obra Triunfo de la libertad sobre el despotismo (1791), que el poder despótico no podía conciliarse con el cristianismo.

(...) me entregué a la lectura y meditación de la Biblia, para instruirme de todos los documentos políticos que en ella se encuentran. (...) Mis miras puramente políticas, nada tenían que hacer con el dogma y demás concernientes al reino de la gracia y de la gloria. Mi fe era invariable en estos puntos (Roscio, 1996: 7).

Con su estudio Roscio introduce la hermenéutica política de los acontecimientos bíblicos, insatisfecho de los comentarios artificiosos 
sobre las Escrituras, que complicarían su sencillez (Roscio, 1996: 7), como él mismo afirma. Este procedimiento reinterpretativo sentaría las bases anticipatorias del método a emplear por los teólogos del desarrollo y de la liberación.

\section{Desarrollo y liberación}

Dos tendencias dominaron el escenario de la teología en los años Sesenta, la teología del desarrollo y la teología de la liberación. Ante la situación de pobreza y atraso socio-económico del continente latinoamericano, una pionera y significativa respuesta fue la "Teología del desarrollo" 3 , iniciada por el dominico Louis-Joseph Lebret (1897-1966), quien se enfocaría a sensibilizar en la Iglesia católica las temáticas del "desarrollo integral del hombre" y de la humanidad.

Para responder al subdesarrollo de los países el padre Lebret, quien mucho trabajó en América Latina desde 1947, no sólo confiaría sus ideas a la pluma, sino que las concretaría en instituciones como el Centro de Investigación y Acción Economía y Humanismo fundado en 1941, para humanizar la economía; y el Instituto Internacional para la Investigación y de Formación, Educación y Desarrollo (IRFED) fundado en 1958, para enseñar métodos y técnicas de investigación a técnicos y políticos provenientes de los países subdesarrollados.

Para el teólogo, nuestra civilización produce una economía política que no está dirigida al ser humano, al contrario, lo ha materializado y esclavizado. De tal manera el padre Lebret crea el ideal de una Economía Humana -de la cual derivaría el movimiento Economie et Humanisme (1941) - como respuesta al economicismo (contra el capitalismo explotador y materialista, no propiamente contra el capital), donde se propone la economía al servicio del hombre y no al revés. Idelfonso Camacho sostiene que el pensamiento de Lebret es relevante por dos razones: "Porque desde sus inquietudes pastorales, fue uno de los pioneros en tema de desarrollo; y porque fue el autor del primer borrador de la Populorum Progressio" (Camacho, 1998: 127). La acción del padre Lebret influye en el cuestionamiento en el seno de la teología respecto a su papel en la historia social del hombre, creando muchos seguidores en toda América Latina, en especial destacan los católicos incorporados al movimiento Acción Católica.

El padre Lebret llegarían a ser considerado como un profeta (Löwy, 1999: 182), dada su posición frontal contra el capitalismo y las realidades

3 Junto a esta teología más dominante se formularon teologías paralelas como la teología de la revolución, la teología de la violencia o la teología del trabajo, con mismas finalidades hacia el desarrollo del hombre integral y la tentativa de acercar los valores del cristianismo al marxismo. 


\section{4 \\ Pasquale Sofia \\ Iglesia católica y política en América Latina: la teología de la liberación}

infrahumanas que se habían generado en el continente, en particular en Brasil donde vivió siete años. Para el padre Lebret lo más grave no era la miseria de los pobres, sino la inconsciencia de los ricos y el escaso interés de la élite política para encontrar soluciones adecuadas. Ante estas consideraciones sobre el capitalismo y la conducta de las élites políticas, el teólogo denuncia además la persistencia del problema de la pobreza al no atacarse sus causas profundas; a partir de estos argumentos, el dominico intenta un acercamiento con la doctrina marxista. Como releva Michael Löwy, el padre Lebret logra "desatanizar" el marxismo frente a muchos católicos brasileños (Löwy, 1999: 182). Si bien él rechazaba por igual el marxismo y el capitalismo, Löwy reporta que, en varias conferencias y cursos dictados sobre todo en Brasil, se expresa sobre el marxismo de la siguiente manera:

No es ni una teoría sin consistencia ni una organización sin pensamiento. Es la expresión en parte admirable y en parte dudosa de una corriente bien caracterizada de aspiraciones de multitudes desorientadas que quieren retomar esperanza (...). El mayor número de reproches que se le hacen caen a un lado; pocos hombres se han tomado el tiempo de analizarlo con seriedad; demasiado pocos son capaces de corregir sus desviaciones y sus defectos" (L'economie humaine, curso dictado en la Escuela Libre de Ciencias Sociales y Política de Sao Paulo, 1947) (Löwy, 1999: 183).

Dentro del debate teológico sobre el desarrollo y el subdesarrollo, emerge también el sacerdote François Houtart quien escribe Hacia una teología del desarrollo (1967). Titulo ya explícito del contenido que va a desenvolver, asumiendo el tema del desarrollo material del hombre dentro de la teología y considerando la doctrina marxista como la base para la lucha al capitalismo imperante. La mencionada teología entra en la disputa entre desarrollo y subdesarrollo, en antagonismo con la teoría de la modernización de las décadas Cincuenta y Sesenta, para encontrar vías de solución a la atávica condición de la pobreza.

El método marxista dela revolución como posibilidad decambio real, sería elegido por los teólogos del desarrollo como el único camino para realizar el profundo cambio que urgía en la región. Con referencia al marxismo, el teólogo Joseph Comblin en su obra Théologie de la Révolution (Teología de la revolución, 1970), asume la revolución como tema teológico, llegando a concluir que lamentablemente no hay otra vía, conectando directamente el subdesarrollo con la salida revolucionaria. El dominico Alex Morelli contrario al uso de la violencia, en su texto Libera a mi pueblo (1971), se refiere a la liberación de las sociedades subdesarrolladas, optando por una "revolución liberadora" no-violenta.

Fueron varios los teólogos vinculados a la Teología del desarrollo que comenzaron a cuestionarse y tomar inspiración para la discusión en América Latina de las teorías del desarrollo y de la dependencia; esta última 
prospectando soluciones de transformación político-económicas en la línea marxista, frente al tema de la modernización. Estas teologías constituyen un preámbulo de la Teología de la Liberación, y la teología del desarrollo marca buena parte de su contenido.

La Teología de la Liberación expresa el compromiso pastoral de la Iglesia latinoamericana con la historia, concentrándose en el ideal de liberación del hombre de las estructuras de dominio, cumpliendo un viraje importante sobre la relación historia del hombre y teología. Estas nuevas inquietudes teológicas en América Latina, desde el punto de vista teórico recibirán influencia de la nueva "Teología Política" de Johann Baptist Metz (1928-2019), quien a su vez se inspiró en su maestro Karl Rahner (19041984) exponente de la Nouvelle Théologie, y en el teólogo luterano Dietrich Bonhoeffer (1906-1945). Ellos aspiraban reconstruir una hermenéutica teológica diferente de la tradicional, más aferrada a la historia política y social del hombre.

Metz acoge de Rahner la teoría del "recentramiento antropológico", en la cual se postula una nueva teología de la praxis histórica en conexión con el mundo real y con la cultura moderna, es decir, en conexión con el hombre. ¿Cómo puede un cristiano hablar adecuadamente de Dios, si no habla al mismo tiempo del hombre? Sería la cuestión central de Rahner. El cristiano según su visión, está en el mundo y es corresponsable en su construcción; está enlazado a la historia inexorablemente. Para Rahner, el Concilio Vaticano II sería la oportunidad de toma de responsabilidad de la Iglesia frente a las inquietudes espirituales y temporales del cristiano contemporáneo. El Concilio aportaría una profunda transformación en la Iglesia católica, pasando de una condición oclusiva hacia la realidad sociopolítica, al reinicio del caminar con la sociedad y dentro de la sociedad.

Se transitaría pues, del centralismo auspiciado por el Concilio Vaticano I (1869), a la promoción de la descentralización, otorgando y reconociendo autonomía a las Iglesias locales, tal y como se enuncia en la constitución dogmática Lumen Gentium (n. 23, 1964) (Maier, 2005: 396). De tal manera que, como afirma Martin Maier, las Iglesias locales luego del Concilio, no serían consideradas ya como simples filiales de Roma (Maier, 2005). La Iglesia universal es una comunidad de Iglesias, o como dice Maier: "Una comunidad de muchas Iglesias locales en comunión", que expresan la unidad en el respeto de las diferencias culturales nacionales. En la Lumen Gentium se afirma en consecuencia:

Por su parte, los Obispos son, individualmente, el principio y fundamento visible de unidad en sus Iglesias particulares [67], formadas a imagen de la Iglesia universal, en las cuales, y a base de las cuales se constituye la Iglesia católica, una y única (n. 23). 


\section{Iglesia católica y política en América Latina: la teología de la liberación}

Respecto a la contribución de Bonhoeffer, Metz toma la idea de que la religión no se convierte en evasión del mundo. En Berlín, en 1932, Bonhoeffer tituló una conferencia Venga a nosotros tu Reino, en la cual reafirmaba la conciencia terrenal del hombre inspirado en Cristo. Sostuvo que Cristo no intenta alejar al hombre de la tierra, o como él mismo dice, "A mundos ideados por la evasión religiosa" (Bonhoeffer, 1985: 102). Al contrario, quiere que viva la terrenalidad a la luz del mensaje divino, reinterpretado luego del paréntesis medieval, afirmando que, a Cristo, Dios: "Lo devuelve a la tierra como hijo fiel" (Bonhoeffer, 1985: 102), donde se manifiesta como amor que no necesita ser impuesto, sino que es un camino del hombre a la exploración de los frutos divinos (Bonhoeffer, 1985: 102-103).

Para la teología tradicional, siendo la realidad socio-política expresión de lo temporal, transitoria y mutable, no es relevante frente a la eternidad del espíritu. Ante esta situación, el rol que asume la nueva teología de la acción según Metz, es de correctivo crítico del modelo metafísico tradicional, demasiado pasivo, acomodador y hasta insensible con la exigencia del hombre en su realidad cotidiana y existencial, lo cual ha generado una separación entre religión y sociedad (Metz, 1969: 1232-1240).

En su obra Teología del Mundo (1970), que contiene el manifiesto programático de la Teología Política, se expresa la relación que debería concretarse entre la Iglesia y el mundo, donde "mundo" tiene el significado de sociedad en camino, en evolución. El teólogo desea salir del aislamiento y "ensimismidad" en la cual estaba recluida la teología clásica, reconociendo la historia, la política y la sociedad a la cual asocia el sentido de la salvación. El apoyo a las nuevas tendencias teológicas y filosóficas latinoamericanas sería relevante por parte de Metz, tanto, que define la II Conferencia de Medellín como cuna de la Teología de la Liberación, y a la teología como conectivo crítico frente a la privatización de la religión.

\section{Los jesuitas y la nueva tendencia teológica latinoamericana}

Los jesuitas, como se ha expuesto, han representado un empuje ascendente en la teorización de la nueva manera de interpretar la fe y su relación con el mundo. El padre Jean-Baptiste Janssens, $27^{\circ}$ General de la Compañía de Jesús, en 1949 publicó Instrucción sobre el apostolado social (Janssens, 1997: 24-34), donde estimula a sus sacerdotes a intervenir en el ámbito social saliendo de los claustros y a vivir con la gente para entender sus problemas. En dicho documento advierte a la Compañía sobre varias amenazas que van del neo-paganismo a la indiferencia religiosa que se transforma en ateísmo, la cual penetra con facilidad en la clase proletaria, problemas que incumben tanto en Europa como en América Latina. De 
igual manera en el ámbito social, observa, por un lado, al liberalismo como incapaz de rescatar de la miseria a los pobres, categoría universalmente extendida; por el otro, señala el peligro del avance del comunismo siempre más organizado y penetrante, sobre todo ante las condiciones de miseria e ignorancia.

Y frente por frente del comunismo ateo está esa otra forma de materialismo, llamado «liberal»; la de los ricos y capitalistas que, sin fe en Dios y en Cristo, o al menos arrinconando o negando esa fe en su vida práctica, sobre todo pública, fomentan sus propios intereses y privilegios más que el bien común de toda la humanidad. (...) A menudo, en vez de la tiranía de un partido político o del Estado, con la que el comunismo se burla de los proletarios, pone el capitalismo la tiranía de poderosísimas sociedades que dejan que el hambre y la miseria atenace a naciones enteras antes que consentir un descenso o una tregua en sus propios ingresos (Janssen, 1997: 3).

Si bien las raíces del apostolado social atraviesan dos milenios de vida cristiana, dice el teólogo, esto es poco tiempo si se mide en función de los diferentes escenarios del mundo del siglo XX. En la Instrucción que proclama como Superior General, alerta a sus cofrades a entrar en la contienda social, solicitando asumir una "actitud diferente", para interpretar más adecuadamente las exigencias y el tormento de la humanidad y, sobre todo: "A capacitarse en aquella caridad activa y sincera que hoy se llama 〈actitud social〉 o 〈mentalidad social〉" (Janssen, 1997: 27).

(...) juntando la teoría con la práctica, se les orienta a los Padres en los ministerios propios de la Compañía. (...) incumbe dirigir las primeras experiencias de los Padres en los ministerios que durante esta probación han de ejercitarse, sobre todo entre los humildes y proletarios. (...) más fácilmente que a los Novicios, concederé, donde los Instructores me lo propongan, que vayan a las fábricas, ya para su ministerio puramente espiritual, ya también para ejercer un oficio manual entre los obreros, pero cuidando de no olvidar nunca su dignidad sacerdotal. Visiten, desde luego, a los obreros y a los pobres, tanto en los Hospitales y Asilos como, con las debidas cautelas, en sus propias casas. Conozcan de vista la miseria de la vivienda, del vestido, del alimento de los pobres. Conozcan su ignorancia e inurbanidad por falta de educación. (...) Es preciso que no pocos de nuestros ministerios sean dirigidos, más eficazmente al proletariado (Janssen, 1997: 12-17).

Según el padre Janssens, para bien interpretar la realidad se precisa conocerla directamente, aprendiendo lo que significa vivir en el medio de las incomodidades e injusticia, del hambre y el desprecio que las situaciones socio-políticas reservan a la mayoría de las personas en todo el mundo. Los hombres de la "periferia del mundo" son la gran mayoría. Por tal motivo, comenta el jesuita Michael Campbell-Johnston, la Congregación no debía solamente proveer lo necesario o fundamental para la sobrevivencia de los pobres, sino principalmente: "Configurar las estructuras mismas de la convivencia humana de modo que alcancen éstas una expresión de mayor justicia y caridad" (Campbell-Johnston, 1997: 9). 


\section{8 \\ Pasquale Sofia \\ Iglesia católica y política en América Latina: la teología de la liberación}

En 1955 el Padre General decide intervenir más directamente en América Latina «de re sociali» (sobre asuntos sociales), para no dejar espacio a los comunistas, según expresa en las Instrucciones, "Si nosotros, incitados por la caridad de Cristo, no trabajamos con denuedo por mejorar esas condiciones de vida, preparamos el camino al comunismo ateo (...)" (Janssen, 199)7: 24). Así en pocos años se crearon varios institutos de estudios y acción sociales -Centro de investigación y acción social, CIASen la mayoría de los países de Latinoamérica, donde muchos jóvenes jesuitas y laicos comenzarían a estudiar las ciencias sociales.

En Lima en 1966, el Padre Pedro Arrupe, nuevo General de la Compañía, sustituto del Padre Janssen fallecido en 1964, convocó reunión de los $\mathrm{CIAS}^{4}$ de América Latina, con la finalidad de enfocar estructuralmente las acciones a realizar; siguiendo la línea de su predecesor, declaraba que el objetivo de esta organización sería la transformación de la mentalidad y de las estructuras sociales, con sentido de justicia social preferentemente en el sector de la promoción popular (Campbell-Johnston, 1997: 11-12).

El padre Arrupe desde el primer momento demostraría su opción de dar a los jesuitas un poderoso impulso, haciéndoles sentir artífices de un nuevo sistema social. En su misión el padre Arrupe expresaría carisma, decisión y claridad, que manifestaría también al apoyar al papa Pablo VI en su camino de renovación eclesial, a la luz del Vaticano II. Es así como se cruzan dentro de la Iglesia dos grandes reformadores: Pablo VI como Pontifex Maximus de los católicos y Pedro Arrupe, como General de una de las más poderosas y transformadoras congregaciones religiosas, que tiene la finalidad de la salvación y perfección de los prójimos. Arrupe, luego de su elección manifestó prontamente el apoyo de la Compañía a la vía ya trazada por el Padre Janssen, respeto al empeño marcadamente social de guerra a la pobreza y a las estructuras que la generan, frente a una posición más conservadora de una parte de los jesuitas ${ }^{5}$.

En mayo de 1968 los Provinciales jesuitas de América Latina se reunieron con el Padre Arrupe, en Rio de Janeiro. En esa ocasión se produjo la Carta de Rio dirigida a los jesuitas del continente y con la ocasión, se fundó en la misma Curia romana el Secretariado para el Desarrollo Socio-Económico (JESEDES). La Carta, influida también por el contenido altamente polémico de la encíclica Populorum Progressio (1967) frente a los temas de la pobreza y del subdesarrollo de los pueblos, fue el compromiso de la Compañía con el mundo latinoamericano. Fue sin duda una ulterior incitación al empeño integral, comunitario y personal para la causa social, y al final los Provinciales declararon que:

4 Ya en 1966 se contaban 24 CIAS en América Latina.

5 Se recuerda que Pedro Arrupe, ganó las elecciones como General de la Compañía de Jesús compitiendo con el ala conservadora de los Jesuitas, representados por el ex rector de la Pontificia Universidad Gregoriana de Roma, el padre Pablo Dezza. 
Quisiéramos insistir sobre la conversión íntima que supone en cada uno de nosotros nuestra participación en la creación de un nuevo orden social. (...) Nunca llegará la construcción de una sociedad más humana, si somos incapaces de llevar este aporte divino, sin el cual toda construcción social vuelve a ser inhumana: ése es el aporte que el mundo espera principalmente de nosotros, sacerdotes y religiosos (punto 10).

En la Carta está explicito el análisis sobre la situación de pobreza y de injusticia social en las cuales viven los latinoamericanos, expresando igualmente una voluntad de cooperación más amplia con el clero y laicos comprometidos, para una pastoral conjunta. Se afirma:

En toda nuestra acción, nuestra meta debe ser la liberación del hombre de cualquier forma de servidumbre que lo oprima: la falta de recursos mínimos y de alfabetización, el peso de las estructuras sociológicas que le quitan su responsabilidad en la vida, la concepción materialista de la existencia. Deseamos que todos nuestros esfuerzos confluyan hacia la construcción de una sociedad, en la que el pueblo sea integrado con todos sus derechos de igualdad y libertad, no solamente políticos, sino también económicos, culturales y religiosos (punto 3).

Para realizar esa integración es importante que la Compañía en su acción de concientización llegue igualmente a:

Los adultos, que deben ser también los promotores del cambio social: intelectuales, empresarios, dirigentes sindicales, artistas, hombres de negocios, profesionales, hombres políticos. Debemos ayudarles a ser auténticos cristianos en su vida profesional y pública, o auténticos profesionales al servicio de la sociedad (punto 8).

Bajo estos presupuestos la Congregación ignaciana se empeña difundir en el continente americano: "La predicación del evangelio de los pobres" (punto 4), y promete actuar en el tejido social según la enseñanza de la Populorum Progressio.

Entiéndasenos bien: la situación presente tiene que afrontarse valerosamente y combatirse y vencerse las injusticias que trae consigo. El desarrollo exige transformaciones audaces, profundamente innovadoras. Hay que emprender, sin esperar más, reformas urgentes. Cada uno debe aceptar generosamente su papel, sobre todo los que, por su educación, su situación y su poder tienen grandes posibilidades de acción (punto 32).

Cuanto se afirma en la Populorum Progressio, se proclama como única manera para alcanzar la paz social (punto 4). Para intervenir dentro de las estructuras sociales es urgente la formación de mentalidades para la acción, sea intelectualmente, sea en la formación de líderes campesinos y obreros, que "protagonicen su propia liberación" (punto 6).

La Carta también invita a los jesuitas a compartir la vida del mismo pueblo para comprenderlo y penetrar dentro de sus necesidades legítimas y reales, para educarlo en sus derechos y en la fe cristiana. 
Pasquale Sofia
60 Iglesia católica y política en América Latina: la teología de la liberación

Nuestros centros de educación deberán ir formando una conciencia de que la colectividad entera se beneficia de sus servicios (...). Infundir en nuestros alumnos primariamente una actitud de servicio a la sociedad, en cuya transformación deben colaborar, y una eficaz preocupación por los marginados, en cuya promoción deben trabajar (punto 7).

Sin embargo, para inicio de la década de los Ochenta, el padre Arrupe da cuenta de la postura asumida por buena parte de sus sacerdotes en América Latina, en el sentido de radicalizar su pensamiento en la línea marxista y aceptar el uso del método de la misma doctrina para la promoción de la justicia. En 1980, envía un comunicado a los provinciales jesuitas de América Latina, en el cual les advierte sobre el uso no conforme a la doctrina cristiana de tal método e inspiración teórica, afirmando:

(...) El adoptar el 'análisis marxista' rara vez significa adoptar solamente un método o un 'enfoque'; significa generalmente aceptar también el contenido mismo de las explicaciones dadas por Marx acerca de la realidad social de su tiempo, aplicándolas a las de nuestro tiempo [...] Llegamos ahora al núcleo de la cuestión ċse puede aceptar el conjunto de las explicaciones que constituyen el análisis social marxista, sin adherirse a la filosofía, a la ideología, a la vaticano política marxista? (...) Con mucha frecuencia el materialismo histórico se entiende en sentido reductor (...) debemos evitar un análisis que suponga la idea de que lo económico, en ese sentido reductor, decide sobre todo lo demás (...) (Arrupe, 1980: 331-338).

Si la producción fuese el fulcro de la vida y de la relación humana como lo expresan los marxistas, la religión y el cristianismo perderían su sentido, se relativizan y hasta aparecerían como inútiles, y la sociedad se convertiría en atea, dice el Padre Arrupe, resaltando la inconciliabilidad epistemológica entre marxismo y cristianismo.

(...) En suma, aunque el análisis marxista no incluye directamente la adhesión a la filosofía marxista en todo su conjunto -y menos todavía al 'materialismo dialéctico' en cuanto tal- sin embargo, tal como se lo entiende de ordinario, implica de hecho un concepto de la historia humana que no concuerda con la visión cristiana del hombre y de la sociedad y desemboca en estrategias que ponen en peligro los valores y las actitudes cristianas (Arrupe, 1980: 331-338).

A pesar de este llamado de advertencia, los jesuitas se pusieron en primera línea frente a las injusticias sociales y al militarismo del siglo XX en América Latina, con el mismo aflato y coraje con los cuales crearon las "reducciones" del siglo XVII, para rescatar a los indios del yugo de los terratenientes coloniales. Pues así, pensaron, estructuraron y practicaron una actualizada evangelización en fiel continuidad con el Concilio Vaticano II. Sustentándose en la Gaudium et Spes, en la cual se afirma que:

Es deber permanente de la Iglesia escrutar a fondo los signos de los tiempos e interpretarlos a la luz del Evangelio, de forma que, acomodándose a cada generación, pueda la Iglesia responder a las perennes interrogantes de la humanidad sobre el sentido de la vida presente y de la vida futura y sobre la mutua relación de ambas (GS n. 4). 
En esta novedosa doctrina se encontraron las bases del apoyo doctrinal y moral irrefutable para reformular las condiciones de la lucha ante las injusticias y las estructuras inicuas y perversas de poder. Si bien la Carta de Rio representa el propio carácter jesuita, aquel probabilismo que caracteriza el empeño sin repensamientos, la lucha frontal es contra lo que se identifica ser el "mal”. Ningún compromiso pues con la política y la economía que no tenga en su visión la derrota de las reiteradas situaciones de injusticia y pobreza del continente. Por otro lado, el comunicado posterior del padre Arrupe representa un freno al entusiasmo hacia el análisis y el método marxista.

\section{Conclusiones}

Luego de la Segunda guerra mundial, en América Latina se manifiesta un contexto político dividido entre autoritarismo, dictaduras y frágiles democracias, en el cual se hacía evidente una situación de dependencia y pobreza, según la mirada crítica de la CEPAL (Comisión Económica para América Latina y el Caribe). La Iglesia católica nace con la finalidad de redimir al hombre del pecado, intención con la cual Cristo la había creado. Ante los fenómenos de la pobreza y de la dependencia, para algunos teólogos como los de la Teología de la Liberación, Cristo vino también para romper las cadenas físicas que mantienen oprimido al hombre de este hemisferio. Por tal finalidad y haciendo hincapié en la "Teología del Éxodo" (la liberación de los judíos por obra de Moisés, de la esclavitud en Egipto), símbolo de la liberación política y en las palabras de Jesús: "Me ha enviado a... poner en libertad a los oprimidos" (Lc 4:18), estaría centrada la dialéctica fe/realidad, que abre la puerta a la teología de la praxis y de la liberación.

Si bien oriunda de América Latina, en el sentido de ser la expresión concreta de la situación socio-política del continente, sus pródromos más cercanos se encuentran en la visión y en la acción, mayormente de la Compañía de Jesús, ante la historia local del hombre. De hecho, en 1949 el General de los Jesuitas, Jean-Baptiste Janssens publicó la guía Instrucciones sobre el apostolado social, donde se instaba a sus sacerdotes en América Latina a la acción social planteada sobre justicia y solidaridad cristiana, para cambiar las estructuras de la convivencia.

A la luz de este planteamiento, se crearon en este hemisferio varios Centros de Investigación y Acción Social (CIAS), con la finalidad de enfocar estructuralmente las acciones a realizar, surgiendo desde estos centros muchas expectativas de cambios en estas sociedades. Es de resaltar la importante figura del Padre Pedro Arrupe, sucesor de Janssens, quien instaría a sus sacerdotes a modificar la mentalidad y las estructuras sociales 
de América Latina, en dirección hacia la justicia social. Arrupe, por medio de la Carta de Rio (1968), influenciada por la polémica encíclica de Pablo VI Populorum Progressio de 1967 ante los temas de la pobreza y del subdesarrollo de los pueblos, afirmaría el compromiso de la Compañía con el mundo latinoamericano. La Carta fue sin duda una ulterior incitación al empeño integral, comunitario y personal por la causa social.

Otros, desde el punto de vista teórico, como el jesuita Karl Ranner plantaba el "recentramiento antropológico" de la teología, es decir regresar por parte de esta a ocuparse no solo de la salvación del hombre, misión central del cristianismo, sino también de la historia del hombre, de su vida relacional, social y política. Su alumno, el teólogo Metz, reinterpreta la Biblia a partir de la historia política del hombre, "desprivatizando" la teología para abrirla al mundo real.

No faltaron otras teologías como antesala o mejor como constituyentes de la Teología de la Liberación, que han contribuido quizás en estimular su forma más radical, como ha sido la "Teología del desarrollo", del sacerdote dominico Louis-Joseph Lebret, que contiene el ideal de una economía al servicio de la humanidad y no para el dominio de esta última. O como la propuesta del sacerdote François Houtart quien escribe Hacia una teología del desarrollo (1967), donde se asume el tema del desarrollo material del hombre dentro de la teología y considerando la doctrina marxista como la base para la lucha al capitalismo imperante.

Las mencionadas teologías entran en la disputa entre desarrollo y subdesarrollo, en antagonismo con la teoría de la modernización de las décadas Cincuenta y Sesenta, para encontrar vías de solución a la atávica condición de la pobreza. Así como también el sacerdote Joseph Comblin en su obra Teología de la revolución (1970), asume la "revolución" como tema teológico, llegando a concluir que lamentablemente no hay otra vía, conectando directamente el subdesarrollo con la salida revolucionaria. En el texto Teología de la práctica de la revolución (1979), Comblin considera que, si bien el concepto de "liberación" es más amplio que el de "revolución", ambos se funden ante la lucha revolucionaria por la emancipación del imperialismo de los países industrializados; y la lucha no puede ser tampoco individual a manera de una guerra de independencia, sino que debe ser Global e involucrar a todos los países sometidos.

En América Latina, además de la Iglesia mística como la anunciaba San Pablo, se manifiesta una Iglesia política y en algunos casos hasta revolucionaria, que ha sido el resultado de una reflexión teológica y filosófica profunda dentro de la misma Institución. Si bien la inquietud de muchos clérigos aparece antes del Concilio Vaticano II (Constitución Pastoral Gaudium et Spes, 1965, promulgada por Pablo VI) y de la encíclica Populorum Progressio, estas han dado base al contenido doctrinal de la Iglesia política latinoamericana. Finalmente, entre las tendencias teológico- 
políticas de la Teología de la Liberación, se hallan, por un lado, las de un frente radical revolucionario que hace hincapié en el método marxista para solucionar los problemas anunciados y, por el otro, las de un frente más equilibrado que apoya una posición no-violenta para resolver los problemas sociales. Ello evidencia una inconciliabilidad doctrinal y de medios políticos entre la doctrina política cristiana y el marxismo.

\section{Referencias Bibliográficas}

ARRUPE, Pedro. 1969. "Carta de los Provinciales de América Latina a los jesuitas del continente" En: Jesuitas Anuario de la Compañía de Jesús 1968-69. Publicado por la Curia Generalicia de la Compañía de Jesús. Roma, Italia.

ARRUPE, Pedro. 1980. "Carta a los Provinciales de América Latina sobre el Análisis Marxista del 08-12-1980” En: Acta Romana Societatis Jesus. Vol.18, No. 01, pp. 123-162.

BONHOEFFER, Dietrich. 1985. Creer y vivir. Sígueme. Salamanca, España.

CAMACHO, Idelfonso. 1998. "El orden económico en los sesenta según la Populorum Progressio, en la Iglesia y el Orden Internacional” En: Memorias del IV Simposio Internacional, Reflexiones a 30 años de la Populorum Progressio. Universidad Iberoamericana. México DF., México.

CAMPBELL-JOHNSTON, Michael. 1997. "Una Breve Historia” En: Promotio Iustitiae, de la Rerum Novarum Al Decreto 4, No. 66, febrero, Roma, pp. 8-24.

COMBLIN, Joseph. 1970. Théologie de la Révolution. Universitaires. Paris, France.

COMBLIN, Joseph. 1979. Teología de la práctica de la revolución. Editorial Desclée De Brouwer. Bilbao, España.

GAUDIUM ET SPES. 1965. Única constitución pastoral del Concilio Vaticano II. Roma, Italia.

HOUTART, Françoise. 1967. Hacia una teología del desarrollo. Bonum. Buenos Aires, Argentina. 
Pasquale Sofia
64 Iglesia católica y política en América Latina: la teología de la liberación

JANSSENS, Jean-Baptiste. 1949. "Las instrucciones sobre el Apostolado Social" En: Promotio Iustitiae, de la Rerum Novarum al Decreto 4. No. 66, febrero, pp. 24-34.

LA BIBLIA LATINOAMERICANA. 1972. Sociedad Bíblica Católica Internacional. Pamplona, España.

LÖWY, Michael. 1999. Guerra de dioses: Religión y política en América Latina. Siglo XXI. México D.F., México.

LUMEN GENTIUM. 1966. Constitución dogmática sobre la Iglesia. Paulianas. Madrid, España.

MAIER, Martin. 1999. "Le devenir de la théologie catholique en Amérique Latine depuis le Concile Vatican II" En: Transversalités, No. 72 (Revue de l'Institut Catholique de Paris), octobre - décembre, pp. 145-168.

MAIER, Martin. 2005. “Karl Rahner y los orígenes de la teología de la liberación” En: Theologica Xaveriana. No. 155, 31 agosto, pp. 395-412.

MARITAIN, Jacques. 1983. El hombre y el Estado. Ediciones Encuentro. Madrid, España.

MARITAIN, Jacques. 2001. Humanismo integral. Palabra. Madrid, España.

METZ, Johann Baptist. 1968. "El problema de una teología política" En: Concilium No. 36, Madrid, pp. 385-403.

METZ, Johann Baptist. 1970. Teología del Mundo. Sigueme. Salamanca, España.

METZ, Johann Baptist. 2002. Dios y tiempo. Nueva teología política. Editorial Trotta. Madrid, España.

MORELLI, Alex. 1971. Libera a mi pueblo. Ediciones C. Lohlé. Buenos Aires, Argentina.

MOUNIER, Emmanuel,1971. El Personalismo. Eudeba. Buenos Aires, Argentina.

PABLO VI. 2006. Populorum Progressio, San Pablo, Bogotá.

PREBISCH, Raúl, 1950. "Crecimiento, desequilibrio y disparidades: interpretación del proceso de desarrollo económico" En: Estudio Económico de América Latina y el Caribe, Naciones Unidas Comisión Económica para América Latina y el Caribe (CEPAL), No.1110, enero, pp. 245-298. 
ROSCIO, Juan German.1996. El triunfo de la libertad sobre el despotismo. Biblioteca Ayacucho. Caracas, Venezuela.

ROSTOW, Walt Whitman.1965. Etapas del crecimiento económico. Fondo de Cultura Económica. México DF., México.

SARANYANA, Josep Ignasi. 2002. Teología en América Latina. El siglo de las teologías latinoamericanistas (1899-2001). Vol. III, Iberoamericana. Madrid, España. 
Vol. $37 \mathrm{~N}^{\circ} 65$

Esta revista fue editada en formato digital y publicada en julio de 2020, por el Fondo Editorial Serbiluz, Universidad del Zulia. Maracaibo-Venezuela 